University of Nebraska - Lincoln

DigitalCommons@University of Nebraska - Lincoln

USGS Staff - Published Research

US Geological Survey

2018

Evaluating the Waterfowl Breeding Population and Habitat Survey for Scaup

Michael L. Schummer

Long Point Waterfowl and Wetlands Research Program/Bird Studies Canada \& SUNY College of

Environmental Science and Forestry, mlschumm@esf.edu

Alan D. Afton

Louisiana State University, Baton Rouge

Shannon S. Badzinski

Environment and Climate Change Canada, Canadian Wildlife Service

Scott A. Petrie

Delta Waterfowl Foundation, Bismarck

Glenn H. Olsen

U.S Geological Survey, Patuxent Wildlife Research Center

See next page for additional authors

Follow this and additional works at: https://digitalcommons.unl.edu/usgsstaffpub

Part of the Geology Commons, Oceanography and Atmospheric Sciences and Meteorology Commons, Other Earth Sciences Commons, and the Other Environmental Sciences Commons

Schummer, Michael L.; Afton, Alan D.; Badzinski, Shannon S.; Petrie, Scott A.; Olsen, Glenn H.; and Mitchell, Mark A., "Evaluating the Waterfowl Breeding Population and Habitat Survey for Scaup" (2018). USGS Staff -- Published Research. 1148.

https://digitalcommons.unl.edu/usgsstaffpub/1148

This Article is brought to you for free and open access by the US Geological Survey at DigitalCommons@University of Nebraska - Lincoln. It has been accepted for inclusion in USGS Staff -- Published Research by an authorized administrator of DigitalCommons@University of Nebraska - Lincoln. 


\section{Authors}

Michael L. Schummer, Alan D. Afton, Shannon S. Badzinski, Scott A. Petrie, Glenn H. Olsen, and Mark A. Mitchell 


\title{
Evaluating the Waterfowl Breeding Population and Habitat Survey for Scaup
}

\author{
MICHAEL L. SCHUMMER,, ${ }^{\mathbf{1 , 2}}$ Long Point Waterfowl and Wetlands Research Program/Bird Studies Canada, Port Rowan, ON NOE 1MO, Canada \\ ALAN D. AFTON, School of Renewable Natural Resources, Louisiana State University, Baton Rouge, LA 70803, USA \\ SHANNON S. BADZINSKI, Environment and Climate Change Canada, Canadian Wildife Service, Ottawa, ON K1A OH3, Canada \\ SCOTT A. PETRIE, Delta Waterfowl Foundation, Bismarck, ND 58504, USA \\ GLENN H. OLSEN, U.S Geological Survey, Patuxent Wildlife Research Center, Laurel, MD 20708, USA \\ MARK A. MITCHELL, ${ }^{3}$ Department of Veterinary Clinical Medicine, University of Illinois, Urbana, IL 61802, USA
}

\begin{abstract}
Potential bias in breeding population estimates of certain duck species from the Waterfowl Breeding Population and Habitat Survey (WBPHS) has been a concern for decades. The WBPHS does not differentiate between lesser (Aythya affinis) and greater (A. marila) scaup, but lesser scaup comprise 89\% of the combined scaup population and their population estimates are suspected to be biased. We marked female lesser scaup (i.e., marked scaup) in the Mississippi and Atlantic Flyways, Canada and United States, with implantable satellite transmitters to track their spring migration through the traditional and eastern survey areas of the WBPHS, 2005-2010. Our goal was to use data independent of the WBPHS to evaluate whether breeding population estimates for scaup were biased and identify variables that might be used in the future to refine population estimates. We found that the WBPHS estimates of breeding scaup are biased because, across years, only $30 \%$ of our marked scaup had settled for the breeding period when the strata in which they settled were surveyed, $43 \%$ were available to be counted in multiple survey strata as their migration continued during the WBPHS, 32\% settled outside the WBPHS area, the number of times a marked scaup was available to be counted by survey crews varied positively with the latitude that a marked scaup settled on breeding areas, the probability of a marked scaup being in a stratum while it was surveyed varied among years, and these probabilities were positively correlated with the traditional and eastern breeding population estimates for scaup. Annual population estimates derived from banding data provide a less biased and preferable method of monitoring scaup population status and trend. Development of models that include metrics such as survey stratum latitude and annual spring environmental conditions might potentially be used to improve scaup breeding population estimates derived from the WBPHS, but independent estimates from banding data would be important to evaluate such models. (c) 2018 The Wildlife Society.
\end{abstract}

KEY WORDS aerial surveys, Aythya affinis, banding, population estimates, satellite telemetry, survey bias, survey coverage.

Reliable wildlife surveys require unbiased estimation procedures to report precise trends in abundance and enable appropriate management responses to changes in breeding populations (Mills 2012). The Waterfowl Breeding Population and Habitat Survey (WBPHS) represents the most extensive wildlife breeding population survey world-wide (Baldassarre and Bolen 2006). The United States Fish and Wildlife Service (USFWS), Canadian Wildlife Service (CWS), and state, provincial, and non-government

Received: 8 April 2017; Accepted: 2 March 2018

${ }^{1}$ E-mail: mlschumm@esf.edu

${ }^{2}$ Present address: Roosevelt Wild Life Station, SUNY College of Environmental Science and Forestry, Syracuse, NY 13120, USA

${ }^{3}$ Present address: School of Veterinary Medicine, Louisiana State University, Baton Rouge, LA 70803, USA cooperators conduct the WBPHS annually during May and June to determine abundance and trends in populations of waterfowl in North America (Smith 1995, Baldassarre and Bolen 2006). Breeding duck populations have been estimated annually since 1955 and 1990 for the traditional and eastern survey areas, respectively. The WBPHS uses airplanes and helicopters to survey waterfowl (USFWS 2016); ground crews also are used in the prairies and parklands to develop annual visibility correction factors ( $\mathrm{VCF}$ ), whereas historical VCF constants from helicopter surveys are used for the boreal (developed 1986-1988) and tundra (developed 1988-1991) regions (Smith 1995). In the eastern survey area, concurrent helicopter surveys were used for estimating annual VCFs to correct data collected from fixed-wing surveys. Internal and external reviews of WBPHS population estimation procedures have been completed (CWS and USFWS 1977, Martin et al. 1979, Bowden 1984, Smith 
1995, Lillegård et al. 2008). However, additional evaluations of the effectiveness of the WBPHS would be useful to continue to inform and refine breeding population estimates for certain species to aid waterfowl conservation efforts in North America (Smith 1995; Afton and Anderson 2001; Austin et al. 2000, 2002; Anderson et al. 2007).

Reconnaissance flights are used in the southern portions of the WBPHS to determine annual survey start dates to provide the best representation of breeding populations for the greatest number of duck species (CWS and USFWS 1977, 1987). The aim of the WBPHS is to start surveys after the majority of transient species migrate north and most latearriving species have settled into breeding territories (CWS and USFWS 1977, 1987). However, in practice, the WBPHS generally coincides with timing of mallards (Anas platyrhynchos) settling on breeding sites (Smith 1995, USFWS 2017). The assumption that the WBPHS accurately describes trends in abundance of all species has been a concern of biologists for decades because of the asynchronous nesting and migration chronologies among species of ducks, especially for late-nesting species or species whose inter-annual variability in migration chronology does not synchronize with mallards (Dzubin 1969, Holland 1997, Afton and Anderson 2001, Austin et al. 2002, Finger et al. 2016). The USFWS maintains the WBPHS database and acknowledges potential bias for late-nesting species, such as lesser scaup (Aythya affinis), to users downloading and using these data (USFWS 2017). Additional surveys for some species have been recommended to reduce bias associated with a single survey (Afton and Anderson 2001, Austin et al. 2002), but increased survey efforts may be limited by increased costs and logistical constraints of the current survey protocol (M. D. Koneff, USFWS, personal communication). Maintaining consistency in survey methodology is important (Cowardin and Blohm 1992), but a periodic review of methods and evaluations of bias are needed. Improvements to surveys and population models also may be required as science-based information on environmental factors influencing waterfowl migration chronology, and timing and locales of settling on breeding sites become available (Cowardin and Blohm 1992, Austin et al. 2002, Mallory et al. 2003, Finger et al. 2016). Evaluations of the WBPHS have become increasingly important because responses (e.g., migration chronology and timing of settling) to climate change are likely to vary among species (Gurney et al. 2011, Drever et al. 2012, Notaro et al. 2016, Osnas et al. 2016, Zhao et al. 2016).

In the traditional survey areas, the WBPHS is typically conducted 1-25 May in the prairies and 12 May-12 June in the boreal forest (Smith 1995). Thus, when weather conditions are not conducive to early migration (Finger et al. 2016), some scaup may not be counted if they migrate behind survey crews, which generally progress from south to north within strata of the WBPHS (Crissey 1975, Mallory et al. 2003). However, in many years, scaup may be counted multiple times if their migration movements overlap the WBPHS crews, or if they are counted on migration and breeding areas (Naugle et al. 2000, Austin et al. 2002,
USFWS 2017). Such annual variation in scaup migration chronology has resulted in inter-annual changes in scaup breeding population estimates from the WBPHS that are not biologically possible given their observed fecundity, nest success, and fledging metrics (Afton and Anderson 2001).

Variation in the annual timing of spring migration by scaup is influenced by temperatures and related ice conditions of lakes, rivers, and large wetland complexes, whereas these attributes generally are less influential in dabbling ducks such as mallards (Austin et al. 2002, Mallory et al. 2003, Schummer et al. 2010, Finger et al. 2016). During spring migration, mallards feed in agricultural fields, shallow wetlands, and shallow depressions in agricultural fields that are flooded by snow melt or rain, even when the ground and lakes remain frozen, which often allows the majority of mallards to migrate well in advance of scaup (Mallory et al. 2003, Baldassarre 2014). However, using 1980-2010 survey data from the North Dakota Game and Fish Department (NDGF), Finger et al. (2016) detected that peak timing of scaup abundance occurred (15 Apr \pm 2 days [SE]) before mallards in 19 of these 31 years, whereas peak scaup abundance only lagged behind mallard abundance in 6 of 31 years (20 Apr \pm 4 days [SE]). Despite this timing of migration in North Dakota prior to the start of the WBPHS, Finger et al. (2016) detected scaup were still migrating through survey strata during the WBPHS and suggested that using mallard chronology to determine timing of the WBPHS could bias breeding population estimates for scaup (Finger et al. 2016).

The breeding range of scaup encompasses nearly the entire traditional survey area and extends into the eastern survey area (Anteau et al. 2014, Baldassarre 2014). A known limitation of the WBPHS is lack of coverage for species that breed in substantial densities outside the survey strata boundaries (Smith 1995, USFWS 2017). Anecdotal evidence suggests that some scaup do settle into breeding areas outside survey strata (M. D. Koneff, personal communication), but no empirical studies have estimated the annual proportions of scaup that breed outside the traditional and eastern survey areas. Variation among years in the number of scaup breeding northeast of the prairie and boreal survey strata, north of the eastern survey area, and in non-surveyed areas of Alaska (Baldassarre 2014) also may increase bias in breeding population estimates for scaup (M. D. Koneff, personal communication).

Our goal was to evaluate whether breeding population estimates for scaup were biased and identify variables that might be used in the future to develop models to refine population estimates. The objectives of our descriptive study were to use satellite telemetry to track migrations of marked female lesser scaup (i.e., marked scaup) through the WBPHS traditional and eastern survey areas to describe 1) proportions of marked scaup located within survey strata when aerial surveys were being conducted in those strata (i.e., proportion available to be counted); 2) proportions of marked scaup that were available to be counted in multiple survey strata throughout migration (i.e., potential for multiple-counting); 3) proportions of marked scaup that had settled for the 
breeding period within survey strata before surveys were conducted in those strata; 4) proportions of marked scaup settling for the breeding period outside of survey strata; and 5 ) if the number of times a marked scaup was potentially available to be counted during the WBPHS was influenced by breeding latitude and settling date.

\section{STUDY AREA}

During March-April in 2005-2010, we captured and marked female lesser scaup $(n=78)$ at important spring migration areas in the Atlantic and Mississippi Flyways, including Lake Erie at Long Point, Ontario, Canada $\left(42^{\circ} 32^{\prime} \mathrm{N}, 80^{\circ} 15^{\prime} \mathrm{W}\right)$ and Presque Isle Bay, Pennsylvania, USA $\left(40^{\circ} 8^{\prime} \mathrm{N}, 80^{\circ} 5^{\prime} \mathrm{W}\right.$; i.e., Lake Erie), and Pool 19 of the Mississippi River in Iowa and Illinois, USA $\left(40^{\circ} 30^{\prime} \mathrm{N}\right.$, $\left.91^{\circ} 20^{\prime} \mathrm{W}\right)$. Long Point and Presquile Bay are important spring stopover areas on Lake Erie for scaup migrating through the Great Lakes region (Prince et al. 1992, Petrie 1998, Knapton and Petrie 1999). Pool 19 is an important middle-latitude migration area for lesser scaup where large numbers stopover prior to migrating through the upperMidwest United States during spring (Thompson 1973, Havera 1999, Anteau 2006). We monitored and evaluated movements of marked scaup during spring migration and throughout the breeding period in Bird Conservation Regions (BCR) 2-4, 6-9, 11-14, 17, 22, and 23 (North American Bird Conservation Initiative 2017). Within these $\mathrm{BCR}$, marked scaup used the traditional (strata 1-18, 19-50, and 75-77) and eastern (strata 51-70) areas of the WBPHS (USFWS 2016; Fig. 1). The traditional survey area covers 3.4 million $\mathrm{km}^{2}$ and includes parts of Alaska, the northcentral United States, and northern Yukon, Northwest Territories, northeastern British Columbia, Alberta, Saskatchewan, Manitoba, and Ontario, Canada (Smith 1995; Fig. 1A). The eastern survey area covers 1.8 million $\mathrm{km}^{2}$ and includes parts of Ontario, Quebec, Labrador, Newfoundland, Nova Scotia, Prince Edward Island, New Brunswick, Canada and the northeastern United States (USFWS 2016; Fig. 1B).

\section{METHODS}

\section{Capture, Marking, and Monitoring Scaup With Satellite Transmitters}

We captured lesser scaup using swim-in and dive-in traps baited with corn, wheat, barley, or a mixture of these grains. We baited traps daily and removed lesser scaup $\geq 2$ times daily from March through April 2005-2010. We determined sex and age (juvenile or adult) of each bird captured using plumage and cloacal examination (Haramis et al. 1982, Olsen et al. 1992, Pace and Afton 1999). We implanted satellite transmitters into a randomly selected sub-sample of adult female lesser scaup $\geq 630 \mathrm{~g}$ (Pool $19[\bar{x}=754 \pm 7 \mathrm{~g}$; range $=630-930 \mathrm{~g}$; \% body mass $\bar{x}=5 \%$; $\%$ body mass range $=4-6 \%]$ ) and $\geq 620 \mathrm{~g}$ (Lake Erie $[\bar{x}=720 \pm 14 \mathrm{~g}$; range $=620-847 \mathrm{~g} ; \%$ body mass $\bar{x}=5 \%$; $\%$ body mass range $=4-6 \%]$ ) that had no visible injuries (Fair et al. 2010).

We used the Argos satellite system to obtain latitude, longitude, date, time, estimated location error classes, and body temperature for marked scaup during spring migration and on breeding areas (Service Argos 2008). Details of duty cycles, use of location classes, and filtering (Douglas-Filter; Douglas et al. 2012) methods were also described in Finger et al. (2016). Argos categorized location observations of marked scaup into 4 location error classes (LC): $<250 \mathrm{~m}$ (LC-3), 250-500 m (LC-2), 501-1,500 m (LC-1), or no information on location accuracy available (LC-0). We used the hybrid Douglas Argos-Filter Algorithm (DouglasFilter) in Movebank to filter satellite location data (Douglas et al. 2012). We retained locations that 1) were closest to previous or immediately prior to newly selected locations (Peterson et al. 1999, Hatch et al. 2000); 2) had a maximum rate of travel of $<100 \mathrm{~km} /$ hours (Miller et al. 2005); 3) had a minimum accepted angle of 15 degrees among 3 subsequent points; 4) were LCs 1-3 to capture complete representation of migration; 5) contained the best location class within a duty cycle (Peterson et al. 1999); and 6) when internal body temperature indicated the duck was still alive.

For designation of settling on a breeding area, we used $8 \mathrm{~km}$ as an indicator threshold of migratory movement, after evaluating all movements of marked scaup and identifying obvious differences in staging and settling movements compared to migratory movements (Finger et al. 2016). We considered a marked scaup settled at the breeding site when it was known to be alive and it exhibited no movement $>8 \mathrm{~km}$ for $\geq 30$ days (Finger et al. 2016). We used 30 days because it slightly exceeded incubation periods for lesser scaup (Afton and Ankney 1991, Austin et al. 2005) and this criterion was used previously to infer settling in other waterfowl (Miller et al. 2005, Krementz et al. 2011, Finger 2013). We included marked scaup in our analyses only if they were alive throughout the WBPHS and settled, or were migrating during the WBPHS and remained in a stratum during the breeding period (i.e., complete migration). We chose to include marked scaup in our analyses that remained longterm in a particular stratum, state, or province (if breeding outside the WBPHS area) during the breeding period of May-August but did not show characteristics of establishing breeding home ranges. Scaup counted during the WBPHS include breeding and non-breeding females, given that some females do not breed annually (Afton 1984, Rotella et al. 2003, Baldassarre 2014, Warren et al. 2014). We plotted where marked scaup were located when the WBPHS was being conducted each year and throughout the breeding period. Because we marked a small portion of the continental lesser scaup population, we created $90 \%, 50 \%$, and $10 \%$ kernel densities to depict estimates of the breeding period locations relative to the WBPHS area for visual comparison with known migration corridors and breeding areas of lesser scaup (ArcMap 10; Environmental Systems Research Institute, Redlands, CA, USA; Baldassarre 2014, Krapu et al. 2014, King et al. 2016).

\section{Sampling Design and Tests of Transmitter Effects}

We monitored female lesser scaup because they typically are paired and migrating to settle on breeding areas, whereas a large proportion of males are unpaired and probably move 
substantial distances throughout the breeding period looking for potential mates (Baldassarre 2014). The WBPHS does not differentiate between greater (Aythya marila) and lesser scaup; however, we marked lesser scaup because $89 \%$ of scaup observed by the WBPHS were estimated to be lesser scaup
(Baldassarre 2014, USFWS 2016). Further, biologists believe that the decline in the scaup population estimate was due to decreased abundance of lesser scaup (Austin et al. 2000). We used 38-g implantable satellite transmitters (Microwave Telemetry, Columbia, MD, USA) because they

A) Pool 19
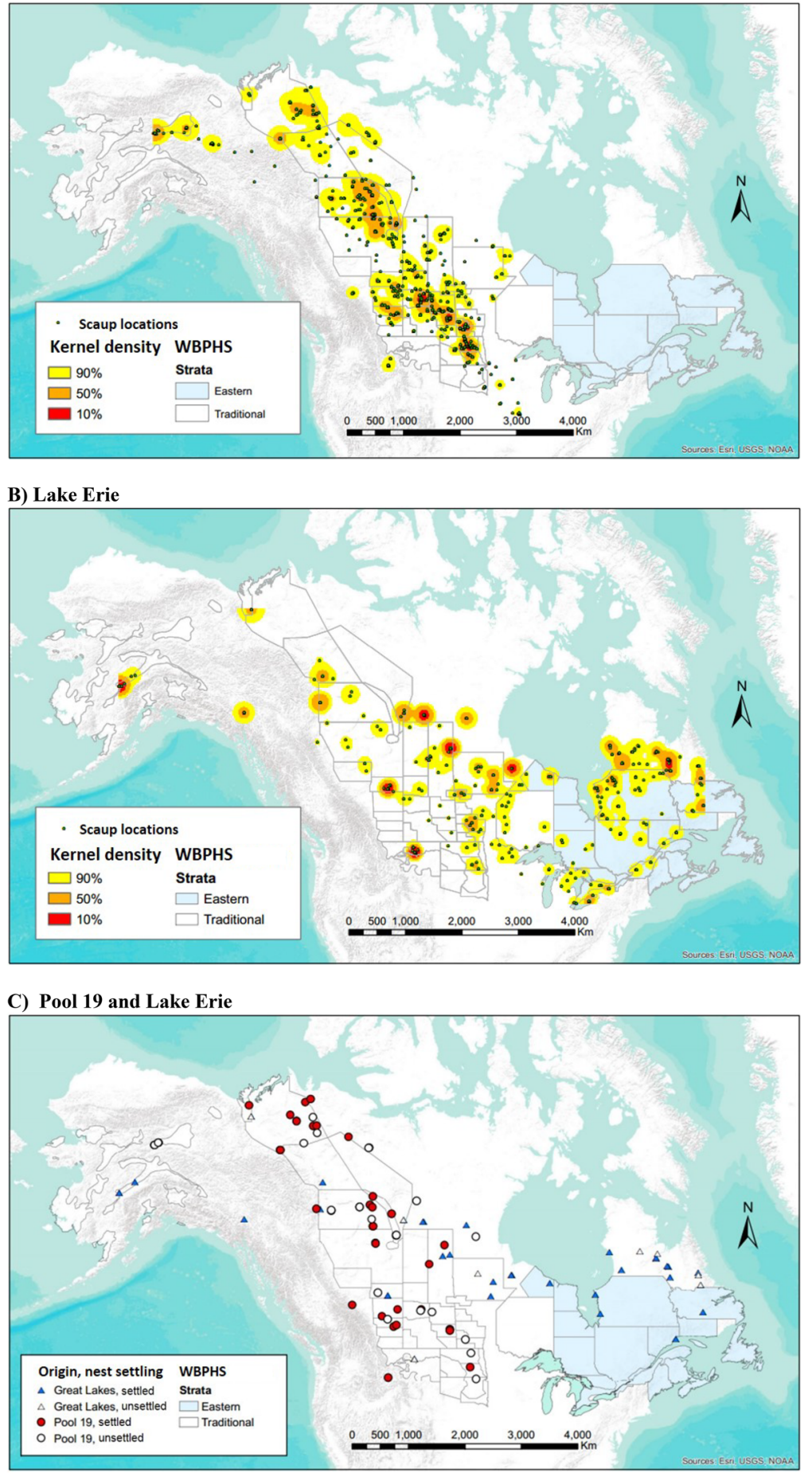

Figure 1. Locations of female lesser scaup during the spring migration and breeding periods marked with satellite-transmitters at Pool 19, (IL and IA, USA) and Lake Erie (Ontario, Canada and PA, USA), 2015-2010. A) Locations of scaup marked at Pool 19 obtained while the Waterfowl Breeding Population and Habitat Survey (WBPHS) was being conducted, May-June. B) Locations of scaup marked at Lake Erie obtained while the WBPHS was being conducted, May-June. C) Locations of scaup marked at Pool 19 of the Mississippi River or Lake Erie that settled on breeding sites $(\boldsymbol{O}=$ Pool 19, $\boldsymbol{\Delta}=$ Lake Erie) or remained in a single stratum (or province or state if breeding outside the WBPHS area; $\circ=$ Pool 19, $\Delta=$ Lake Erie) at the end of migration (i.e., unsettled). 
were the lightest available with an estimated battery life that would allow monitoring of lesser scaup for $>1$ year. Two veterinarians (i.e., G. H. Olsen, M. A. Mitchell) working among study sites used identical and standard surgical methods to implant the satellite transmitters with a percutaneous antenna into each lesser scaup (Olsen et al. 1992, Mulcahy and Esler 1999). Our study was approved by the Louisiana State University (LSU) Institutional Animal Care and Use Committee (protocol number 07-012), United States Geological Survey (USGS) Federal Bird Banding permit (number 08810), Illinois Department of Natural Resources (scientific permit number W07.0237-W14.0237), Ontario Ministry of Natural Resources Animal Care and Use Committee (protocol 06-106), and the Canadian Wildlife Service scientific permit (number CA.0171). Transmitters were $4-6 \%$ of body mass, which is appropriate (Fair et al. 2010), and were approved by Animal Care and Use Committees at LSU. At Pool 19, we marked lesser scaup $>400 \mathrm{~km}$ south of the WBPHS survey strata for $\geq 32$ days $(\bar{x}=42 \pm 3.4$ [SD] days) prior to the beginning of the survey. At Lake Erie, we marked lesser scaup in stratum 54 for $\geq 14$ days ( $\bar{x}=35 \pm 12.6$ days) prior to the beginning of the survey. Despite differences in marking locations and timing prior to the start of the WBPHS, we did not detect a difference in probability of a marked scaup being available to be counted between marking locations (see Results). Cox and Afton (1998) recommended a recovery period of 8 days, which our sample exceeded by several weeks. Thus, we believe the amount of time that lesser scaup were marked prior to the WBPHS enabled them to acclimate to the telemetry units.

Implanting telemetry units in our sample of lesser scaup could potentially affect migration chronology, especially in the season they were initially marked, and thus, possibly cause differences in migration among years. Accordingly, we used analysis of variance (ANOVA) a priori to test if the number of times a marked scaup was available to be counted differed between individuals that provided data for only 1 migration, and those monitored for 2 or 3 migrations (PROC GLM, SAS Institute 2009). To test for additional chronic effects in marked scaup that provided data for 2 or 3 spring migrations, we used ANOVA to test if the number of times individual marked scaup were available to be counted differed among these migrations and evaluated whether the percentage of these marked scaup settling in the same strata for the breeding period differed among years.

\section{Locations of Scaup During the WBPHS and Analysis of Migration Chronology}

We obtained and imported spatial layers of WBPHS strata into ArcMap 10 (K. K. Fleming, USFWS, unpublished data). We also obtained dates of transect flights by strata, 2005-2010 (M. D. Koneff, unpublished data). In the traditional survey area, each stratum contained 2-18 aerial transects $(n=330)$, which were each subdivided into shorter segments. Observers in aircraft count ducks along each transect within $200 \mathrm{~m}$ of each side of the aircraft. Area surveyed was calculated from area enclosed in each transect and generally ranged from $0.2 \%$ to $2.0 \%$ of stratum area (Smith 1995). In the eastern survey area, airplanes (USFWS) and helicopters (CWS) were used to conduct surveys (Bordage et al. 2003, Zimmerman et al. 2012). We used only the timing of USFWS transect flights because helicopters were not used throughout the WBPHS area (Zimmerman et al. 2012). During 2005-2010, the traditional survey began on 2-6 May in the south, and ended between 8 and 22 June in the north and the eastern survey began on 1 or 6 May in the south, and ended between 29 May and 13 June in the north.

We used the location class of each marked scaup location to determine if the buffer error circle (Finger et al. 2016) bisected strata boundaries, but this never occurred in our sample, so we were able to designate all locations in our sample to a single stratum. For each marked scaup, we determined mean annual percentages \pm standard errors (SE) for 1) the number of times it was located in a stratum when transects were being flown in that stratum (i.e., available to be counted);2) whether it migrated ahead of survey crew and settled at their breeding period site prior to that stratum being surveyed; 3) whether it was available to be counted where it settled for the breeding period; and 4) if its location was outside the WBPHS.

We acknowledge that use of stratum-level analyses could over-estimate the number of times marked scaup were available to be counted because they did not need to be within transects to be considered available to be counted in our analysis. We used our sample of marked scaup as a representation of the movements of the larger population, which would likely be spread throughout a stratum and among transects during surveys. Indeed, stratum-level analysis has been previously used and recommended (Austin et al. 2002, Miller et al. 2003), and our analysis and those of Finger et al. (2016) suggested that our marked scaup were representative of the distribution and timing of larger segments of the populations migrating through the WBPHS strata.

We used a generalized linear mixed model to assess whether the number of times a marked scaup was available to be counted was influenced by latitude of settling and by date of settling (PROC MIXED, SAS Institute 2009). For marked scaup that had not settled at breeding period sites (i.e., did not meet our breeding criterion) and remained in a stratum, state, or province for the summer (Jun-Aug), we defined their settling latitude as their latitude on the last day of the WBPHS. We included survey area (traditional or eastern) as a fixed variable in the model to determine variation attributable to their migration route, and year as a covariate to account for variation among survey years.

We used logistic regression to determine whether the probability marked scaup were available to be counted was potentially influenced by stratum size (PROC GLIMMIX, SAS Institute 2009) because strata of varying size could bias our analysis. We assigned each marked scaup a 1 if it was in a stratum during the range of dates that stratum was being surveyed and a 0 if the marked scaup was in a stratum when it was not being surveyed. In this model, we included the 
number of days a stratum was surveyed and the number of days a marked scaup remained in a stratum as fixed variables to identify the potential for migratory and settling behavior of marked scaup to influence survey results, and if the length of time a stratum was surveyed could influence probability that a marked scaup was available to be counted. We also included survey area (traditional or eastern) and year in the model as fixed variables to control for variation attributable to migration corridor and determine if variation in the probability that a marked scaup was available to be counted varied among survey years. After detecting an influence of year, we tested for correlation between our mean annual model-predicted probability of a marked scaup being available to be counted and the survey population estimate for scaup in the traditional and eastern survey areas (Roberts and Padding 2017).

For all analyses, we included a bird identification number as a repeated measure to account for sampling the same marked individual within and among years, designated alpha $(\alpha)$ a priori as 0.10 (Tacha et al. 1982, Arnold 2010), reported model-predicted values $( \pm \mathrm{SE})$ unless otherwise noted, and used studentized residual plots to determine that all models approximated a normal distribution (Littell et al. 2007).

\section{RESULTS}

Our dataset included 49,325 locations from 78 marked scaup (Pool $19 n=45$; Lake Erie $n=33$ ). After applying the Douglas-filter, there were 7,403 locations from marked scaup that migrated in the WBPHS traditional survey area ( $n=63$ scaup) and 1,092 locations in the eastern survey area ( $n=15$ scaup). Of these marked scaup, 54 and 12 ducks met our criteria and made $\geq 1$ complete spring migration through the traditional and eastern survey areas, respectively. Some marked scaup had telemetry units that lasted only 1 spring migration (Pool $19 n=21$ marked scaup, Lake Erie $n=15$ marked scaup), whereas others had telemetry units that lasted $>1$ migration (Pool $19 n=18$ scaup, Lake Erie $n=8$ marked scaup), which resulted in 102 migrations that were included in our analyses (Pool $19 n=57$ migrations; Lake Erie $n=45$ migrations). We did not detect a difference $\left(F_{1,100}=1.38, P=0.24\right)$ in the number of times marked scaup were available to be counted between those available for monitoring for 1 migration $(\bar{x}=1.25$ $\pm 0.16)$ and marked scaup providing data for multiple years $(\bar{x}=1.47 \pm 0.11)$. For these marked scaup, the number of times they were available to be counted was similar among migrations $\left(F_{3,98}=0.70, P=0.55\right.$; first migration $\bar{x}=1.50 \pm 0.17$; second migration $\bar{x}=1.50$ \pm 0.16 ; third migration $\bar{x}=1.10 \pm 0.30$ ) and $90 \%$ of these marked scaup settled in the same survey stratum among years. Thus, if there were biases resulting from marking our scaup, those biases were arguably minimal, especially given Finger et al. (2016) results that indicated our sample was representative of scaup moving through the traditional survey area. Timing of migration of our marked scaup also was strongly correlated with timing of peak migration of scaup observed in North Dakota Game and Fish Department (NDGF) roadside surveys (Finger et al. 2016).
All scaup marked at Pool 19 migrated through the traditional survey area (Fig. 1A), whereas those marked at Lake Erie migrated through the traditional $(n=27$ marked scaup) and eastern ( $n=18$ marked scaup) survey areas (Fig. 1B). In the traditional and eastern survey areas, $74.3 \pm 10.9 \%$ (SE) and $70.8 \pm 16.4 \%$ met our criteria for settling to breed among years, respectively. Among years, most marked scaup migrating through the traditional survey area settled during the breeding period within the WBPHS area $(83.0 \pm 4.8 \%)$, whereas $36.1 \pm 15.2 \%$ of marked scaup migrating east settled during the breeding period in the eastern survey area (Fig. 1C). For marked scaup using the traditional survey area, $29.5 \pm 6.0 \% \quad(n=29$ migrations $)$ migrated ahead of the WBPHS crew and settled in the stratum where they were available to be counted once. In the eastern survey area, this occurred for 1 of 18 marked scaup migrations across the 5 years of our study. In the eastern survey area, nearly half of our marked scaup across years (44.4\%; 8 of 18 migrations) and $29.2 \pm 15.2 \%$ among years migrated ahead of the WBPHS, were never located in a stratum when it was surveyed, and settled north of the WBPHS area (Fig. 1B, C). Of the 84 marked scaup migrations through the traditional survey area, $13.5 \pm 6.7 \%$ of these migrating scaup were never located in a stratum when it was being surveyed. Most marked scaup migrating through the traditional survey area were available to be counted once ( $49.6 \pm 5.7 \% ; n=35$ migrations) or twice ( $35.7 \pm 5.3 \% ; n=30$ migrations), but some were available to be counted 3 (5.3 $\pm 3.0 \% ; n=10$ migrations) and 4 times $(2.8 \pm 2.8 \% ; n=1$ migration). In the eastern survey area, $54.2 \pm 15.2 \%$ of the marked scaup ( $n=7$ migrations) were available to be counted once, whereas, fewer were available to be counted twice ( $16.7 \pm 10.5 \% ; n=3$ migrations) and no marked scaup were available to be counted $\geq 3$ times.

The number of times a marked scaup was available to be counted increased by $32.4 \pm 4.8 \%$ for each $5^{\circ} \mathrm{N}$ it settled for the summer $\left(F_{1}, 102=4.82, \quad P=0.03\right.$; model-predicted range $=0.75-1.89$; Table 1$)$. The number of times a marked scaup was available to be counted increased by $7.6 \pm 0.3 \%$ for each 5 days later it settled for the summer $\left(F_{1,102}=6.56\right.$, $P<0.01 ; 5$ days was the mean amount of time it took to survey a stratum; Table 1). The model-predicted mean number of times a marked scaup was available to be counted in the traditional survey area $(\bar{x}=1.63 \pm 0.11)$ was $71.6 \%$ greater than those migrating through the eastern survey area $\left(\bar{x}=0.95 \pm 0.19 ; F_{1,102}=9.83, P<0.01\right)$.

Table 1. Model parameter estimates ( $\theta)$, standard errors, and $90 \%$ confidence intervals of variables influencing the number of times a satellite-telemetry marked, female lesser scaup was available to be counted during the Waterfowl Breeding Population and Habitat Survey, 2005-2010.

\begin{tabular}{lrcc}
\hline Parameter & $\boldsymbol{\theta}$ & SE & \multicolumn{1}{c}{$\mathbf{9 0 \%}$ CI } \\
\hline Intercept & -1.846 & 0.949 & $-3.422,-0.270$ \\
Latitude of settling & 0.030 & 0.014 & $0.007,0.052$ \\
Date of settling & 0.012 & 0.005 & $0.004,0.019$ \\
Location & & & \\
$\quad$ Traditional & -0.683 & 0.218 & $-1.044,-0.321$ \\
$\quad$ Eastern & 0.000 & & \\
\hline
\end{tabular}


Table 2. Model parameter estimates $(\theta)$, standard errors, and $90 \%$ confidence intervals of variables influencing probability of a satellite-telemetry marked, female lesser scaup being available to be counted in a stratum during the Waterfowl Population and Breeding Habitat Survey, 2005-2010.

\begin{tabular}{lccc}
\hline Parameter & $\boldsymbol{\theta}$ & SE & $\mathbf{9 0 \%}$ CI \\
\hline Intercept & -2.284 & 0.594 & $-3.278,-1.290$ \\
Number of days a scaup was in a stratum & 0.155 & 0.021 & $0.120,0.191$ \\
Number of days a stratum was surveyed & 0.293 & 0.082 & $0.155,0.043$ \\
Year & & & $-1.993,0.726$ \\
2005 & -0.633 & 0.823 & $-2.535,-0.197$ \\
2006 & -1.366 & 0.708 & $-2.611,-0.613$ \\
2007 & -1.612 & 0.605 & $-2.422,-0.592$ \\
2008 & -1.507 & 0.554 & $-1.487,0.107$ \\
2009 & -0.690 & 0.483 & \\
2010 & 0.000 & & \\
\hline
\end{tabular}

Throughout the migration of our sample of marked scaup, neither stratum size $(P=0.57)$ nor survey area (traditional or eastern; $P=0.26$ ) influenced whether a marked scaup was in a stratum during a survey, whereas the probability that a marked scaup was in a stratum during a survey varied among years $\left(F_{5,226}=2.19, P=0.06\right)$ and was positively associated with the amount of time it spent in the stratum $\left(F_{1}\right.$, $\left.{ }_{226}=53.10, P<0.01\right)$ and the number of days crews took to survey that stratum $\left(F_{1,226}=12.26, P<0.01\right.$; Table 2$)$. On average, marked scaup spent 9.90 days \pm 0.61 (SE) in a stratum prior to the end of the WBPHS (range $=1-51$ days; median =6) and survey crews spent 4.41 days \pm 0.11 (SE) surveying a stratum (range $=1-9$ days; median $=4$ ). Probability of a marked scaup being in a stratum when it was surveyed was $17.8 \pm 2.1 \%$ if it used a stratum for 1 day; for each additional day it remained in a stratum, the probability of a marked scaup being in a stratum when it was surveyed increased by $2.4 \pm 2.0 \%$ with a probability of $42.0 \pm 4.0 \%$ at 10 days (the mean number of days a marked scaup remained in a stratum) and $100.0 \pm 0.1 \%$ after 36 days a marked scaup was in a stratum. The probability that a marked scaup was in a stratum when it was surveyed was $25.0 \pm 8.2 \%$ if a stratum was surveyed for one day; for each additional day it took to survey a stratum, the probability of being in a stratum when it was surveyed increased by $4.0 \pm 2.5 \%$ with a probability of $57.2 \pm 5.6 \%$ at 9 days (the maximum number of days it took to survey a stratum). Lastly, we detected correlation between annual model-predicted probabilities of a marked scaup being in a stratum when it was surveyed and the survey population estimate for scaup in the traditional and eastern survey areas $(r=0.78, P=0.03$; Table 3$)$.

\section{DISCUSSION}

We showed that the probability a marked scaup was available to be counted in a stratum when that stratum was being surveyed varied among years. Further, estimates produced by the WBPHS are based on the assumption that ducks migrate ahead of survey crews, and subsequently settle at breeding sites where they are then available to be counted once the area is surveyed (Smith 1995). However, only $14.7 \%$ of migrations by our marked scaup across years met that criteria, indicating that use of stratum-scale breeding population estimates of scaup for determining their breeding distribution, changes in distributions, and locations for focused conservation efforts is clearly problematic (e.g., Hobson et al. 2009; Ross et al. 2012; Barker et al. 2014a, b). We also found that the number of times a marked scaup was available to be counted varied positively with date of settling during the breeding period. We think this could have partially resulted from substantial variation in the range of dates when surveys concluded. The start date of the WBPHS in the traditional and eastern survey areas, respectively, across our 6-year study was only adjusted by 6 and 8 days (2-6 May and 1-8 May), whereas the end date varied by 15 and 16 days (8-22 Jun and 29 May-13 Jun), which could result in scaup that breed at higher latitudes having more opportunities to migrate with the survey crews and be available to be counted. One of our goals was to use environmental predictors of date of settling outlined in Finger et al. (2016) and determine metrics from this study that could be used in the future to refine WBPHS scaup population estimates. Austin et al. (2002), Mallory et al. (2003), and Finger et al. (2016) suggested using weather data to adjust the population estimates of the WBPHS, but we caution against such an approach given the clear biases we detected. Development of models that include metrics such as survey stratum latitude and annual spring environmental conditions might potentially be used to improve scaup breeding population estimates derived from the WBPHS, but independent annual population estimates derived from banding data would be

Table 3. Waterfowl Breeding Population and Habitat Survey breeding population estimates (in thousands) for scaup in the traditional and eastern surveys areas and mean predicted probability of a satellite-telemetry marked, female lesser scaup being in a survey stratum when that stratum was being surveyed, $2005-2010$.

\begin{tabular}{ccccc}
\hline Year & Traditional & Eastern & Traditional + eastern & Predicted probability (\%) \\
\hline 2005 & $3,386.9$ & 30.0 & $3,416.9$ & 45.5 \\
2006 & $3,246.7$ & 36.9 & $3,286.6$ & 34.7 \\
2007 & $3,452.2$ & 31.3 & $3,483.5$ & 38.9 \\
2008 & $3,738.3$ & 32.5 & $3,770.8$ & 41.6 \\
2009 & $4,172.1$ & 38.4 & $4,210.5$ & 45.5 \\
2010 & $4,244.4$ & 51.1 & $4,296.5$ & 63.5 \\
\hline
\end{tabular}


necessary to evaluate such models (Arnold et al. 2016, 2017; Koons et al. 2017).

Use of the WBPHS data to infer spatial changes in breeding populations of scaup is clearly not appropriate (e.g., Afton and Anderson 2001; Ross et al. 2012; Barker et al. 2014a, b) because, as documented (this study, Finger et al.2016), they are still migrating to their breeding sites during the WBPHS. We detected that nearly half ( $48.8 \%$ of the total migrations) of our marked scaup using the traditional survey area were available to be counted more than once as they migrated north with the WBPHS crew. The number of times a marked scaup was available to be counted in the traditional survey area varied from 0 to 4 times, whereas nearly $50 \%$ of the scaup we marked during our study $(\bar{x}=29.2 \%$ across years; range $=0-83 \%)$ in the eastern survey area migrated ahead of the WBPHS crews, settled north of the WBPHS area, and were never available to be counted. These key findings further highlight the problem of using scaup breeding population estimates produced by the WBPHS as the only metric to estimate their population trend.

The distribution of scaup from autumn through spring has shifted substantially in the past 2 decades with some of the greatest increases in abundance and residency time occurring in the Great Lakes region (Petrie and Knapton 1999, Afton and Anderson 2001, Petrie and Schummer 2002). These shifts and increases have largely been related to increased abundance of invertebrate foods directly or indirectly resulting from colonization of the Great Lakes by invasive zebra (Dreissena polymorpha) and quagga mussels ( $D$. bugensis; Hamilton and Ankney 1994, Austin et al. 2000, Schummer et al. 2008). In addition, substantial declines in ice cover on the Great Lakes during the same period likely increased access to these abundant food resources and potential residency time of scaup in the Great Lakes region (Petrie and Schummer 2002, Assel et al. 2003, Duguay et al. 2006, Wang et al. 2012). Our analysis of the eastern survey area indicates that scaup using these important wintering and staging areas of the Great Lakes are grossly underestimated in the WBPHS because nearly $50 \%$ of our marked scaup migrated ahead of the survey and settled in Quebec, from the northern boundary of the WBPHS to approximately $58.5^{\circ} \mathrm{N}$.

We found that marked scaup that migrated farther north to settle and settled later were available to be counted in strata being surveyed more often than those settling at more southern latitudes or earlier in spring. Thus, scaup settling to breed in the southern portion of their range in parkland and prairie habitats are less likely to be counted multiple times. The number of scaup nesting in parkland and prairie habitats increased during the late-1990s and early-2000s, potentially because of high-philopatry in scaup and greater reproductive success in southern portions of the scaup range during these periods (M. L. Szymanski, NDGF, unpublished data; F. C. Rohwer, Delta Waterfowl Foundation, personal communication; Hammell 2016). Lipid reserves of scaup, used to fuel spring migration, have declined with declining wetland quality (e.g., amphipod abundance) in the upper Midwest of the United States (Anteau and Afton 2004, 2009, 2011; Anteau 2006). If scaup migrate behind the WBPHS crew or settle at lower latitudes because lipid reserves for migration are not adequate or limiting, our results predict this could result in underestimates of the scaup population. Additional information on cross-seasonal mechanisms influencing timing of migration and settling latitude of scaup would help clarify if and how changes in quality of habitats used by scaup are influencing WBPHS population estimates.

After controlling for the number of days a survey crew was in a stratum and individual differences in migration behavior among marked scaup, we determined that the probability that marked scaup were in a stratum when it was being surveyed, differed among years. We suspect this finding was due to scaup migration rarely corresponding with that of mallards (Finger et al. 2016), spring weather conditions varying greatly among years (Johnson et al. 2005), and the timing of the WBPHS primarily being based on that of mallard migration and settling (Smith 1995). Differences between mallard and scaup migration may result in variation in scaup population estimates that do not reasonably reflect actual changes in their breeding population. The USFWS tested for and did not detect an influence of environmental conditions on scaup breeding population estimates (Boomer and Johnson 2006), but these were cursory tests that used data derived from the WBPHS. In contrast, our use of marked scaup data represents a novel approach that was independent of the WBPHS. We detected correlation between model-predicted probabilities of marked scaup being available to be counted and yearly WBPHS population estimates for scaup. In conclusion, we believe our results clearly indicate that WBPHS estimates for scaup are biased. Analysis of banding data including Lincoln estimates can provide more precise and efficient population estimates (Alisauskas et al. 2014, McAlister et al. 2017).

\section{MANAGEMENT IMPLICATIONS}

We recommend that WBPHS breeding population estimates alone not be used to inform population assessments or harvest management for scaup. We suggest that increased effort to band scaup and conduct band analyses to produce precise and efficient population estimates is a desirable alternative to use of the WBPHS for scaup (e.g., annual banding need $=5,000$ scaup; T. W. Arnold, University of Minnesota, unpublished data). Retrospective analyses also might be used that incorporate transect latitude and annual differences in environmental variables to determine if these variables reduce or remove the unrealistic annual changes in scaup population estimates produced by the WBPHS, but evaluation of these models also would benefit from independent population estimates produced from banding data analysis. The spatial focus for conserving breeding habitat for scaup and scaup research needs refinement. Our marked scaup indicated that nearly $50 \%$ of scaup breeding in the eastern survey area may be unaccounted for during the survey. We suggest caution because of our small sample size of scaup migrating through eastern survey area $(n=18$ migrations from 12 scaup), but if our marked sample is representative of the population, current WBPHS estimates minimize the region's contribution to continental scaup populations and its focus area for conservation efforts. As 
previously suggested, we also confirmed that lesser scaup are still migrating during the WBPHS; thus, stratum densities produced from the current survey should not be used to prioritize breeding habitat conservation for scaup. Our models could be used to determine proportions of scaup estimated to be settled and migrating by stratum, which would be helpful in prioritizing habitat conservation for scaup migratory and breeding habitats.

\section{ACKNOWLEGMENTS}

Any use of trade, firm, or product names is for descriptive purposes only and does not imply endorsement by the U.S. Government. We thank anonymous reviewers and the Associate Editor for comments that greatly improved our manuscript. We thank the following individuals for their assistance; K. Savides developed the figures of scaup locations; T. A. Finger filtered and managed data; J. S. Bergman, P. J. Gregory, A. W. Hancock, D. D. Hoffman, D. J. Holm, M. J. Jones, R. K. Leonard, R. W. Marshalla, S. E. Jenkins, J. T. Lamer, D. C. Douglas, and numerous volunteer banders assisted the Pool 19 Project. We thank the following agencies and groups for providing funding and in kind services to the Pool 19 Scaup Project: Upper Mississippi River and Great Lakes Joint Venture, Prairie Pothole Joint Venture, U.S. Fish and Wildlife Service Regions 2 and 3, Minnesota Department of Natural Resources, USGS-Louisiana Cooperative Fish and Wildlife Research Unit, Louisiana State University, Louisiana Department of Wildlife and Fisheries, USGS Patuxent Wildlife Research Center, University of Illinois College of Veterinary Medicine, USGS-Northern Prairie Wildlife Research Center, Iowa Department of Natural Resources, Illinois Department of Natural Resources, Ducks Unlimited, Kibbe Research Station of Western Illinois University, Ontario Ministry of Natural Resources, Canadian Wildlife Service, Missouri Department of Conservation, Des Moines and Louisa County Conservation Boards, Tri Oak Foods, Cargill Corporation, Mississippi Valley Callers Association, Brockway Mechanical and Roofing, Greater Blue Heron Wildlife Refuge, Gulf Coast Joint Venture, North Dakota Game and Fish Department (NDGF), and Minnesota Waterfowl Association. We also thank the following agencies for providing funding and assistance with the Lake Erie Scaup Project: Long Point Waterfowl and Wetlands Research Program of Bird Studies Canada, by way of the Bluffs Hunting Club, The Waterfowl Research Foundation, Ducks Unlimited Canada, Ontario Federation of Anglers and Hunters, Ontario Power Generation, Sydenham Conservation Foundation, Sydenham Sportsmen's Association, Long Point and Area Fish and Game Club, Long Point Waterfowlers' Association, Aylmer Order of Good Cheer, Chip Pitfield, the Canadian Wildlife Service, Pennsylvania Game Commission, NDGF, and USGS Patuxent Wildlife Research Center.

\section{LITERATURE CITED}

Afton A. D. 1984. Influence of age and time on reproductive performance of female lesser scaup. Auk 101:255-265.
Afton, A. D., and M. G. Anderson. 2001. Declining scaup populations: a retrospective analysis of long-term population and harvest survey data. Journal of Wildlife Management 65:781-796.

Afton, A. D., and C. D. Ankney. 1991. Nutrient reserve dynamics of breeding lesser scaup: a test of competing hypotheses. Condor 93:89-97.

Alisauskas, R. T., T. W. Arnold, J. O. Leafloor, D. L. Otis, and J. S. Sedinger. 2014. Lincoln estimates of mallard (Anas platyrhynchos) abundance in North America. Ecology and Evolution 4:132-143.

Anderson, M. G., J. E. Austin, A. D. Afton, J. S. Barclay, R. G. Clark, M. D. Koneff, and S. M. Slattery. 2007. Lesser scaup, greater scaupprospectus for an action team. North American Waterfowl Management Plan Science Support Team, U.S. Fish and Wildlife Service, Arlington, Virginia, USA.

Anteau, M. J. 2006. Ecology of lesser scaup and amphipods in the upper Midwest: scope and mechanisms of the spring condition hypothesis and implications for migration habitat conservation. Dissertation, Louisiana State University, Baton Rouge, USA.

Anteau, M. J., and A. D. Afton. 2004. Nutrient reserves of lesser scaup (Aythya affinis) during spring migration in the Mississippi flyway: a test of the spring condition hypothesis. Auk 121:917-929.

Anteau, M. J., and A. D. Afton. 2009. Lipid reserves of lesser scaup (Aythya affinis) migrating across a large landscape are consistent with the "spring condition" hypothesis. Auk 126:873-883.

Anteau, M. J., and A. D. Afton. 2011. Lipid catabolism of invertebrate predator indicates widespread wetland ecosystem degradation. PLoS ONE 6:e16029.

Anteau, M. J., J.-M. DeVink, D. N. Koons, J. E. Austin, C. M. Custer, and A. D. Afton. 2014. Lesser scaup (Aythya affinis). Account 338 in P. G. Rodewald, editor. The birds of North America. Cornell Lab of Ornithology, Ithaca, New York, USA.

Arnold, T. W. 2010. Uninformative parameters and model selection using Akaike's Information Criterion. Journal of Wildlife Management 74:1175-1178.

Arnold, T. W., A. D. Afton, M. J. Anteau, D. N. Koons, and C. A. Nicolai. 2016. Temporal variation in survival and recovery rates of lesser scaup. Journal of Wildlife Management 80:850-861.

Arnold, T. W., A. D. Afton, M. J. Anteau, D. N. Koons, and C. A. Nicolai. 2017. Temporal variation in survival and recovery rates of lesser scaup: a response. Journal of Wildlife Management 81:1142-1148.

Assel, R., K. Cronk, and D. Norton. 2003. Recent trends in Laurentian Great Lakes ice cover. Climatic Change 57:185-204.

Austin, J. E., A. D. Afton, M. G. Anderson, R. G. Clark, C. M. Custer, J. S. Lawrence, J. B. Pollard, and J. K. Ringelman. 2000. Declining scaup populations: issues, hypotheses, and research needs. Wildlife Society Bulletin 28:254-263.

Austin, J. E., C. M. Custer, and A. D. Afton. 2005. Lesser scaup. Pages 679-685 in J. Kear, editor. Bird families of the world: ducks, geese and swans. Oxford University Press, Oxford, England.

Austin, J. E., D. A. Granfors, M. A. Johnson, and S. C. Kohn. 2002. Scaup migration patterns in North Dakota relative to temperatures and water conditions. Journal of Wildlife Management 66:874-882.

Baldassarre, G. 2014. Ducks, geese and swans of North America. John Hopkins University Press, Baltimore, Maryland, USA.

Baldassarre, G. A., and E. G. Bolen. 2006. Waterfowl ecology and management. Second edition. Krieger, Malbar, Florida, USA.

Barker, N. K. S., S. G. Cumming, and M. Darveau. 2014a. Models to predict the distribution and abundance of breeding ducks in Canada. Avian Conservation and Ecology 9:7. https://doi.org/10.5751/ACE00699-090207

Barker, N. K. S., S. M. Slattery, M. Darveau, and S. G. Cumming. $2014 b$. Modeling distribution and abundance of multiple species: different pooling strategies produce similar results. Ecosphere 5:1-24.

Boomer, G. S., and F. A. Johnson. 2006. A proposed assessment and decision making framework to inform scaup harvest management. Adaptive Harvest Management Working Group, 29 November 2006, Kansas City, Missouri, USA.

Bordage, D., C. Lepage, and S. Orichefsky. 2003. Black duck joint venture helicopter survey-Québec. Canadian Wildlife Service Report Quebec Region, Environment Canada, St. Foy, Canada.

Bowden, D. C. 1984. A review of some statistical aspects of the waterfowl breeding population survey. U.S. Fish and Wildlife Service, Washington, D.C., USA. 
Canadian Wildlife Service and U.S. Fish and Wildlife Service [CWS and USFWS]. 1977. Standard operation procedures for aerial Waterfowl Breeding Ground Population and Habitat Surveys in North America, unpublished manual. U.S. Fish and Wildlife Service, Laurel, Maryland, USA.

Canadian Wildlife Service and U.S. Fish and Wildlife Service [CWS and USFWS]. 1987 Standard operation procedures for aerial Waterfowl Breeding Ground Population and Habitat Surveys in North America, unpublished manual as revised. U.S. Fish and Wildlife Service, Laurel, Maryland, USA.

Cowardin, L. M., and R. J. Blohm. 1992. Breeding population inventories and measurements of recruitment. Pages $423-445$ in B. D. J. Batt, A. D. Afton, M. G. Anderson, C. D. Ankney, D. H. Johnson, J. A. Kadlec, and G. L. Krapu, editors. Ecology and management of breeding waterfowl. University of Minnesota Press, Minneapolis, USA.

Cox, R. R. Jr., and A. D. Afton. 1998. Effects of capture and handling on survival of female northern pintails. Journal of Field Ornithology 69:276-287.

Crissey, W. F. 1975. Determination of appropriate waterfowl hunting regulations. U.S. Bureau of Sport Fisheries and Wildlife Administrative Report-June 21, 1975, Washington, D.C., USA.

Douglas, D. C., R. Weinzierl, S. C. Davidson, R. Kays, M. Wikelski, and G. Bohrer. 2012. Moderating Argos location errors in animal tracking data. Methods in Ecology and Evolution 3:999-1007.

Drever, M. C., R. G. Clark, C. Derksen, S. M. Slattery, P. Toose, and T. D. Nudds. 2012. Population vulnerability to climate change linked to timing of breeding in boreal ducks. Global Change Biology 18:480-492.

Duguay, C. R., T. D. Prowse, B. R. Bonsal, R. D. Brown, M. P. Lacroix, and P. Ménard. 2006. Recent trends in Canadian lake ice cover. Hydrological Processes 20:781-801.

Dzubin, A. 1969. Assessing breeding populations of ducks by ground counts. Saskatoon Wetlands Seminar. Canadian Wildlife Service Report Series 6:178-237.

Fair, J., E. Paul, and J. Jones, editors. 2010. Guidelines to the use of wild birds in research. Ornithological Council, Washington, D.C., USA.

Finger, T. A. 2013. Environmental factors influencing spring migration chronology of lesser scaup (Aythya affinis). Thesis University of Western Ontario, London, Ontario, Canada.

Finger, T. A., A. D. Afton, M. L. Schummer, S. A. Petrie, S. S. Badzinski, M. A. Johnson, M. L. Szymanski, K. J. Jacobs, G. H. Olsen, and M. A. Mitchell. 2016. Environmental factors influence lesser scaup migration chronology and population monitoring. Journal of Wildlife Management 80:1437-1449.

Gurney, K. E. B., R. G. Clark, S. M. Slattery, N. V. Smith-Downey, J. Walker, L. M. Armstrong, S. E. Stephens, M. Petrula, R. M. Corcoran, K. H. Martin, K. A. DeGroot, R. W. Brook, A. D. Afton, K. Cutting, J. M. Warren, M. Fournier, and D. N. Koons. 2011. Time constraints in temperate-breeding species: influence of growing season length on reproductive strategies. Ecography 34:628-636.

Hamilton, D. J., and C. D. Ankney. 1994. Consumption of zebra mussels Dreissena polymorpha by diving ducks in Lakes Erie and St. Clair. Wildfowl 45:159-166.

Hammell, G. 2016. Reproductive rates in lesser scaup (Aythya affinis) in southwestern Manitoba: another look at the data. Canadian FieldNaturalist 130:110-121.

Haramis, G. M., E. L. Derleth, and D. G. McAuley. 1982. Techniques for trapping, aging and banding wintering canvasbacks. Journal of Field Ornithology 53:342-351.

Hatch, S. A., P. M. Meyers, D. M. Mulcahy, and D. C. Douglas. 2000. Performance of implantable satellite transmitters in diving seabirds. Waterbirds 23:84-94.

Havera, S. P. 1999. Waterfowl of Illinois: status and management. Phoenix Publishing, Urbana, Illinois, USA.

Hobson, K. A., M. B. Wunder, S. L. Van Wilgenburg, R. G. Clark, and L. I. Wassenaar. 2009. A method for investigating population declines of migratory birds using stable isotopes: origins of harvested lesser scaup in North America. PLoS ONE 4:e7915.

Holland, M. M. 1997. Characteristics of wetlands and used by breeding diving ducks in eastern South Dakota. Thesis, South Dakota State University, Brookings, USA.

Johnson, W. C., B. V. Millett, T. Gilmanov, R. A. Voldseth, G. R. Guntenspergen, and D. E. Naugle. 2005. Vulnerability of northern prairie wetlands to climate change. BioScience 55:863-872.
King, D. T., J. Fischer, B. Strickland, W. D. Walter, F. L. Cunningham, and G. Wang. 2016. Winter and summer home ranges of American white pelicans (Pelecanus erythrorhynchos) captured at loafing sites in the southeastern United States. Waterbirds 39:287-294.

Knapton, R. W., and S. A. Petrie. 1999. Changes in distribution and abundance of submerged macrophytes in the Inner Bay at Long Point, Lake Erie: implications for foraging waterfowl. Journal of Great Lakes Research 25:783-798.

Koons, D. N., T. W. Arnold, and M. Schaub. 2017. Understanding the demographic drivers of realized population growth rates. Ecological Applications 27:2102-2115.

Krapu, G. L., D. A. Brandt, P. J. Kinzel, and A. T. Pearse. 2014. Spring migration ecology of the mid-continent sandhill crane population with an emphasis on use of the Central Platte River Valley, Nebraska. Wildlife Monograph 189:1-41.

Krementz, D. G., K. Asante, and L. W. Naylor. 2011. Spring migration of mallards from Arkansas as determined by satellite telemetry. Journal of Fish and Wildlife Management 2:156-168.

Lillegård, M., S. Engen, B. E. Sæther, V. GrØtan, and M. C. Drever. 2008. Estimation of population parameters from aerial counts of North American mallards: a cautionary tale. Ecological Applications 18:197-207.

Littell, R. C., G. A. Milliken, W. W. Stroup, R. D. Wolfinger, and O. Schabenberger. 2007. SAS for mixed models. Second edition. SAS Institute, Cary, North Carolina, USA.

Mallory, M. L., L. A. Venier, and D. McKenney. 2003. Winter weather and waterfowl surveys in north-western Ontario, Canada. Journal of Biogeography 30:441-448.

Martin, F. W., R. S. Pospahala, and J. D. Nichols. 1979. Assessment and population management of North American migratory birds. Pages 187-239 in J. Cairns Jr., G. P. Patil, and W. E. Waters, editors. Environmental biomonitoring, assessment, prediction, and management-certain case studies related to quantitative issues. International Co-operative Publication House, Burtonsville, Maryland, USA.

McAlister, M. A., C. S. DePerno, J. C. Fuller, D. L. Howell, and C. E. Moorman. 2017. A comparison of field methods to estimate Canada goose abundance. Wildlife Society Bulletin 41:685-690.

Miller, M. R., J. Y. Takekawa, J. P. Fleskes, D. L. Orthmeyer, M. L. Casazza, and W. M. Perry. 2005. Spring migration of northern pintails from California's Central Valley wintering area tracked with satellite telemetry: routes, timing and destinations. Canadian Journal of Zoology 83:1314-1332.

Miller M. R., J. Y. Takekawa, D. L. Orthmeyer, J. P. Fleskes, M. L. Casazza, and W. M. Perry 2003. Tracking spring migration of northern pintails with satellite telemetry. Final Report. USGS Western Ecological Research Center, Sacramento, California, USA.

Mills, S. L. 2012. Conservation of wildlife populations: demography, genetics, and management, second edition. Wiley Blackwell, Hoboken, New Jersey, USA

Mulcahy, D. M., and D. Esler. 1999. Surgical and immediate postrelease mortality of harlequien ducks (Histrionicus histrionicus) implanted with abdominal radio transmitters with percutaneous antennae. Journal of Zoo and Wildlife Medicine 30:397-401.

Naugle, D. E., R. R. Johnson, T. R. Cooper, M. M. Holland, and K. F. Higgins. 2000. Temporal distribution of waterfowl in eastern South Dakota: implications for aerial surveys. Wetlands 20:177-183.

North American Bird Conservation Initiative. 2017. Bird Conservation Regions. http://www.nabci.net/International/English/bcrmap.html. Access ed 6 Jan 2017.

Notaro, M., M. Schummer, Y. Zhong, S. Vavrus, L. Van Den Elsen, J. Coluccy, and C. Hoving. 2016. Projected influences of changes in weather severity on autumn-winter distributions of dabbling ducks in the Mississippi and Atlantic Flyways during the twenty-first century. PLoS ONE 11:e0167506.

Olsen, G. H., F. J. Dein, G. M. Haramis, and D. G. Jorde. 1992. Implanting radio transmitters in wintering canvasbacks. Journal of Wildlife Management 56:325-328.

Osnas, E. E., Q. Zhao, M. C. Runge, and G. S. Boomer. 2016. Crossseasonal effects on waterfowl productivity: implications under climate change. Journal of Wildlife Management 80:1227-1241. 
Pace, R. M., and A. D. Afton. 1999. Direct recovery rates of lesser scaup banded in northwest Minnesota: sources of heterogeneity. Journal of Wildlife Management 63:389-395.

Peterson, M. R., W. W. Larned, and D. C. Douglas. 1999. At-sea distribution of spectacled eiders: a 120-year-old mystery resolved. Auk 116:1009-1020.

Petrie, S. A. 1998. Waterfowl and wetlands of Long Point Bay and Old Norfolk County: present conditions and future options for conservation. Norfolk Land Stewardship Council Report, Long Point Waterfowl, Port Rowan, Ontario, Canada.

Petrie, S. A., and R. W. Knapton. 1999. Rapid increase and subsequent decline of zebra and quagga mussels in Long Point Bay, Lake Erie: possible influence of waterfowl predation. Journal of Great Lakes Research 25:772-782.

Petrie, S. A., and M. L. Schummer. 2002. Waterfowl response to zebra mussels on the lower Great Lakes. Birding 34:346-351.

Prince, H. H., P. I. Padding, and R. W. Knapton. 1992. Waterfowl use of the Laurentian Great Lakes. Journal of Great Lakes Research 18:673-699.

Roberts, A. J., and P. I. Padding. 2017. Atlantic Flyway harvest and population survey data book. U.S. Fish and Wildlife Service, Laurel, Maryland, USA. https://www.fws.gov/migratorybirds/pdf/surveys-anddata/DataBooks/AtlanticFlywayDatabook.pdf. Accessed 6 Jan 2017.

Ross, B. E., M. B. Hooten, and D. N. Koons. 2012. An accessible method for implementing hierarchical models with spatio-temporal abundance data. PLoS ONE 7:e49395.

Rotella, J. J., R. G. Clark, and A. D. Afton. 2003. Survival of female lesser scaup: effects of body size, age, and reproductive effort. Condor 105:336-347.

SAS Institute. 2009. SAS/STAT user's guide. SAS Institute, Cary, North Carolina, USA.

Schummer, M. L., R. M. Kaminski, A. H. Raedeke, and D. A. Graber. 2010. Weather-related indices of autumn winter dabbling duck abundance in middle North America. Journal of Wildlife Management 74:94-101.
Schummer, M. L., S. A. Petrie, and R. C. Bailey. 2008. Interaction between macroinvertebrate abundance and habitat use by diving ducks during winter on northeastern Lake Ontario. Journal of Great Lakes Research 34:54.

Service Argos. 2008. User's manual. Service Argos, Landover, Maryland, USA.

Smith, G. W. 1995. A critical review of the aerial and ground surveys of breeding waterfowl in North America. Biological Science Report 5, National Biological Service, Washington, D.C., USA.

Tacha, T. C., W. D. Warde, and E. P. Burnham. 1982. Use and interpretation of statistics in wildlife journals. Wildlife Society Bulletin 10:355-362

Thompson, D. 1973. Feeding ecology of diving ducks on Keokuk Pool, Mississippi River. Journal of Wildlife Management 37:382-389.

U.S. Fish and Wildlife Service [USFWS]. 2016. Waterfowl population status, 2016. U.S. Department of the Interior, Washington, D.C., USA.

U.S. Fish and Wildlife Service [USFWS]. 2017. Waterfowl Breeding Population and Habitat Survey: Traditional Survey. https://migbirdapps. fws.gov/mbdc/databases/mas/aboutmas.htm. Accessed 14 Nov 2017.

Wang, J., X. Bai, H. Hu, A. Clites, M. Colton and B. Lofgren. 2012. Temporal and spatial variability of Great Lakes ice cover, 1973-2010. Journal of Climate 25:1318-1329.

Warren, J. M., K. A. Cutting, J. Y. Takekawa, S. E. De La Cruz, T. D. Williams, and D. N. Koons. 2014. Previous success and current body condition determine breeding propensity in lesser scaup: evidence for the individual heterogeneity hypothesis. Auk 131:287-297.

Zhao, Q., E. Silverman, K. Fleming, and G. S. Boomer. 2016. Forecasting waterfowl population dynamics under climate change-does the spatial variation of density dependence and environmental effects matter? Biological Conservation 194:80-88.

Zimmerman, G. S., J. R. Sauer, W. A. Link, and M. Otto. 2012. Composite analysis of black duck breeding population surveys in eastern North America. Journal of Wildlife Management 76:1165-1176.

Associate Editor: Adam Janke. 